\title{
Postgraduate medical training: getting patients on board
}

\author{
Jennifer Heathcote
}

\begin{abstract}
Objectives To survey family planning clinic (FPC) patients who may be involved in the Diploma of the Faculty of Family Planning (DFFP) practical training; to obtain their views about the process of giving consent to their involvement; and to compare their views with current practice.
\end{abstract}

Methods Questionnaire surveys of 103 female FPC patients and 40 DFFP instructing doctors. Patients were recruited from the waiting room of a community FPC, and DFFP instructing doctors from the North West of England were recruited at an updating meeting.

Results Patients felt strongly that they wanted to know what to expect before deciding whether to agree to be involved in the training. Several items of information were requested. The most important of these were whether the training doctor would be seeing the patient alone; the gender of the training doctor; and the training doctor's level of experience. Patients had not always been given this information.

Conclusions Clinical experience is an important part of postgraduate medical training and patients need to be able to give fully informed consent to their involvement. The information currently given to patients may be insufficient. A reluctance to see male training doctors may have implications as regards the breadth of experience gained by male training doctors; this needs further investigation. Further research including different patient populations could inform guidelines for patient involvement in training.

Keywords DFFP, patient consent, postgraduate, training

J Fam Plann Reprod Health Care 2007; 33(4): 267-270

(Accepted 7 March 2007)

\section{Introduction}

Patients have always been part of medical education, but we should not assume that they will always choose to participate. ${ }^{1}$ There are few published studies of patient experiences of postgraduate medical training; most refer to medical student education. This study looked at patients' experiences with post-registration doctors, mainly general practice registrars, who attend family planning clinics (FPCs) to gain clinical experience towards their Diploma of the Faculty of Family Planning (DFFP). These doctors all work with experienced Faculty 'instructing doctors' and patient contact varies from observation of consultations to taking consultations, and may include performing invasive procedures.

Involvement in doctor training is voluntary, so it is important to make the patients' experience as positive as possible. ${ }^{2}$ This study highlights a number of issues that must be considered before patients agree to a training doctor being involved in their care, and asks whether current practice is fulfilling patients' expectations.

\section{Methods}

Patients were recruited from the waiting room of a community FPC serving a mid-sized town in a rural part of Cheshire, UK. A questionnaire that had been pre-piloted in the same clinic sought quantitative and qualitative data about patients' experiences and expectations of their role in DFFP training.

Patients were initially approached by the receptionist on arrival at the clinic, and those who expressed an interest in taking part in the study were seen by the researcher. Further information was given verbally and in writing, and if the patient was able to give fully informed consent then the questionnaire was filled in by the patient

Central and Eastern Cheshire Primary Care Trust, Family Planning Clinic, Macclesfield District General Hospital, Macclesfield, UK

Jennifer A Heathcote, MA, FFFP, Staff Grade

Correspondence to: Dr Jennifer Heathcote, Family Planning

Clinic, Macclesfield District General Hospital, Victoria Road,

Macclesfield, Cheshire SK10 3BL, UK.

E-mail: drjennyheathcote@hotmail.com

\section{Key message points}

- Patients expect to be asked whether they would be prepared to be involved in doctor training.

- Patients do not always receive the information they need in order to make this decision.

in privacy. Most questionnaires were completed in the clinic, but stamped addressed envelopes were provided for patients who wished to return them later. The questionnaires were completely anonymous. Patients were recruited from each of the different types of FPC within the service to obtain a representative sample of the patient population.

A different anonymous questionnaire was distributed at a doctors' updating day to seek the views and practice of instructing doctors from North West England. The aims of the study were described briefly at the start of the meeting, and completed questionnaires were collected as the doctors departed at the end of the day.

\section{Ethical approval}

Ethical approval for the study was granted by the Cheshire Local Research Ethics Committee.

\section{Results}

Forty completed doctors' questionnaires were returned. Since not all the doctors at the meeting were instructing doctors, it is not possible to say whether all the instructing doctors present completed a questionnaire. Replies were received from doctors working on training programmes in general practice, community FPCs and a Brook clinic.

A total of 103 patient questionnaires were returned. Six patients who were initially approached by the receptionist declined to take part in the study. There was no further participant dropout. A high response rate increases the likelihood that the replies are representative of the clinic population. All returned questionnaires were usable, and all the data were included in the final results. Patient quotes have been reproduced verbatim. The age distribution of respondents was shown to be representative when compared to the age distribution of clinic attendees for the year ending 31 March 2005. 


\section{Table 1 Age of clinic respondents}

\begin{tabular}{ll}
\hline Age group (years) & Study population (\%) \\
\hline$\geq 16$ & 11 \\
$17-30$ & 47 \\
$31-45$ & 38 \\
$\geq 46$ & 4 \\
\hline
\end{tabular}

Twenty-seven patients had seen training doctors in the past. One patient said that they had seen a training doctor without being asked first, and one could not remember. The remainder had all been asked.

Most (90\%) of the patients included in the study felt that it was quite important or very important that they were asked before they saw a training doctor.

"On the occasion I have been seen by a training doctor, I was at the GP surgery and hadn't been told there would be anyone in the room. I had gone about a personal problem and actually made up another minor reason for going. It was a big shock to find someone else in the room." (Patient 31)

Ninety-seven patients said that they would be willing to see a training doctor at least sometimes or were undecided. They were asked what information they felt they needed to know. The results are summarised in Table 2.

Patients were given the opportunity to suggest any other information; one wanted to be informed should the training doctor wish to use their case for research, and another asked whether any procedure would need to be performed more than once because of the presence of the training doctor.

\section{Who will be in the consulting room?}

Some $93 \%$ of patients wanted to know whether the instructing doctor would be in the consulting room with the training doctor; $49 \%$ of doctors routinely gave this information. Two-thirds (66\%) of patients would prefer the instructing doctor to stay in the room while they were seeing the training doctor, $4 \%$ would prefer to see the training doctor on their own and $27 \%$ did not mind. A few patients $(3 \%)$ gave provisos, such as:

"Depends on type of appointment - if a coil fitted would like instructing doctor to be there - if check up or discussion, might not be necessary." (Patient 47)

Of those patients who had seen a training doctor in the past, 21 would prefer the instructing doctor to stay in the room while they were seeing the training doctor, one would prefer to see the training doctor on their own and five did not mind.

\section{Gender of the training doctor}

Seventy-six percent of patients wanted to know the gender of the training doctor. Several patients mentioned needing time for mental preparation before seeing a male training doctor, for example:
"As long as I know beforehand I would feel unsure about seeing a male training doctor. But, although I have never been in this position - a friend of mine was - not sure if it was here or another surgery/clinic but she was asked as she went in and it was very awkward for her to say no so important asked prior to this." (Patient 13)

A high percentage $(78 \%)$ of doctors said that the commonest reason that patients gave for refusing to see a training doctor was that the training doctor was male. This was the information most likely to be given during the consenting process, with $74 \%$ of doctors giving it. Several doctors made comments that suggested that they would be more likely to mention gender if the training doctor was male.

One-quarter $(27 \%)$ of doctors estimated that $5-10 \%$ of patients refused to see training doctors; all of the supplementary comments referred to higher refusal rates with male training doctors.

"But relatively more if the training doctor is male and less if the training doctor is female." (Doctor 29)

“... depends on sex of training doctor, if male 5-10\%, if female <5\%." (Doctor 13)

Eight percent of doctors reported a refusal rate of between $11 \%$ and $50 \%$, with training doctor gender being the most important issue.

\section{Level of experience of the training doctor}

Three-quarters $(75 \%)$ of patients wanted to know about the training doctor's experience; $49 \%$ of doctors would discuss this during the consenting process. This was particularly important where the patient anticipated a physical examination or an invasive procedure.

"If the appointment involved a 'physical' rather than 'informative/decision making' activity, e.g. fitting Mirena/implant, then it would be helpful to know the stage of training if training doctor was carrying it out. Could affect the decision." (Patient 53)

\section{Instructing doctor's name}

Seventy percent of patients wanted to know the identity of the instructing doctor.

"I feel patients would be more likely to agree to the presence of a training doctor if they were very familiar with the instructing doctor rather than both doctors being unknown to the patient. With confidence in the instructing doctor I would be far more likely to agree." (Patient 68)

\section{Discussion}

These findings suggest that patients are not always being given the information they want before consenting to a training doctors' involvement in their care. There have been calls for more research in this area ${ }^{1,3}$ and for the

Table 2 Information that patients want to know before they agree to see a training doctor

\begin{tabular}{llll}
\hline Information & Need to know (\%) & Would be useful to know (\%) & Would not need to know (\%) \\
\hline $\begin{array}{l}\text { Name of the training doctor } \\
\text { Sex of the training doctor }\end{array}$ & 14 & 52 & 34 \\
$\begin{array}{l}\text { How experienced the training doctor is in } \\
\text { family planning }\end{array}$ & 38 & 38 & 24 \\
$\begin{array}{l}\text { Whether the training doctor will be seeing the } \\
\text { patient on their own }\end{array}$ & 67 & 51 & 25 \\
$\begin{array}{l}\text { Whether the senior instructing doctor will be } \\
\text { present in the room with the training doctor }\end{array}$ & 63 & 23 & 10 \\
$\begin{array}{l}\text { Name of the senior instructing doctor } \\
\text { nam }\end{array}$ & 16 & 30 & 7 \\
\hline
\end{tabular}


production of suitable guidelines for use within the National Health Service. 1

It was difficult to decide what terminology to use to describe the DFFP training doctors. In the Macclesfield clinic they are usually introduced as 'fully qualified doctors who are taking a higher qualification in family planning'; the term training doctor is rarely used with patients. This was explained to patients before they completed the questionnaire. This difficulty is not unique to this situation. Ubel et al. working in the USA felt it necessary to explain the different levels of doctor training at the beginning of each patient interview in order to obtain informed consent. ${ }^{4}$

Seventy-one percent of patients wanted to know something about a training doctor's experience in family planning, a similar proportion to that recorded in the study by Santen et al. where $80 \%$ of patients in an emergency department felt it was very important to know their physicians' level of training. 5 (The researchers went on to find that only $58 \%$ of patients were actually aware of it.) Giving this information in a way that is meaningful to our patients is not easy.

It may be more relevant to FPC patients to describe the training doctors' experience in terms of posts held, for example: "Dr $\mathrm{X}$ is a doctor working in the gynaecology department at the hospital and is taking an extra qualification in family planning". When terms such as 'senior house officer' or 'registrar in general practice' are used they have not been widely understood. Howe and Anderson found that patients had little understanding of medical training on which to base their expectations of a student's capabilities. ${ }^{1}$ This may become particularly important in a FPC when a training doctor is to perform a procedure.

"My last consultation was to have the Mirena coil fitted and as this is a skilled and painful procedure I would not wish it to be carried out by a training doctor." (Patient 66)

Lack of experience does not necessarily mean that patients will refuse to see students. In a study of medical students performing their first practical procedures, Santen et al. found that $90 \%$ consented even when the student was very inexperienced, but $66 \%$ thought they should be told if the student was performing the procedure for the first time on them. ${ }^{6}$

O'Flynn and Rymer, in their study of gynaecology outpatients, commented: "In contrast to much teaching practice, women expressed a preference for a doctor to be present when they saw a student". ${ }^{3}$ It is interesting to note that this still holds true with DFFP training doctors who are qualified doctors. It may be because patients have not understood the training doctors' level of experience. Doctors need to be aware of the strong patient preference for the instructing doctor to be present during consultations.

The small number of patients who had seen a training doctor in the past were more likely to want an instructing doctor to be present in future consultations [i.e. $78 \%$ $(21 / 27)$ vs $66 \%(50 / 76)]$. It would be interesting to know what experiences had prompted this and it emphasises the importance of involving patients in the decision as to whether the instructing doctor is present during a consultation.

Results from the doctors' questionnaire suggest that the information given to patients across the region is generally similar to that given in Macclesfield, however the demographics of this population are quite unusual and may limit the generalisability of the findings. Some $28.4 \%$ of the population are educated to degree level or beyond compared to the national average of $19.8 \%$, and the population includes few from ethnic minority groups, being over $98 \%$ white. ${ }^{7}$ This may have a particular influence on the acceptability of male training doctors to female patients, since studies have suggested a stronger preference for a female gynaecologist by some ethnic groups. ${ }^{8,9}$

The rate of refusal to see a training doctor in Macclesfield is about 3\%, with the majority of refusals being because the training doctor is male. This is a fairly low rate (one of the regional doctors estimated their refusal rate to be about $20 \%$ ), but in clinics with higher refusal rates there must be concern about the quality and breadth of experience that some male training doctors receive. This has been raised in the teaching of male medical students. O'Flynn and Rymer found that gynaecology clinic patients would allow significantly more female students to observe or examine their genital area than males ( $60 \%$ vs $43 \%) .10$ Grant too found that male students were significantly more likely to experience patient refusals in an obstetrics and gynaecology clinic. ${ }^{11}$

Seamark and Blake's study in general practice showed that women had a greater preference for a female doctor when attending for 'women's problems'.12 Quilliam confirms a preference to consult a female doctor for sexual health-related concerns. ${ }^{13}$ There is anecdotal evidence that some women choose to attend a FPC because they anticipate that they will see a woman doctor. Adolescent girls wanting contraception have been shown to prefer seeing a female doctor or nurse. ${ }^{14}$ Some FPC patients attend our clinic - where all of the doctors currently happen to be female - because they cannot always guarantee a female doctor when they visit their general practitioner.

It may be pertinent to ask whether patients would agree to see male training doctors if they knew more about them, or if they felt that they could choose whether to consent for all, or only certain aspects, of their consultation. When asked whether she would be more or less likely to agree to see a male training doctor, one patient commented:

“... depends what appointment for ... would want to be accompanied by female doctor as well". (Patient 45)

Patients may be less willing to see male training doctors without the instructing doctor or a chaperone being present, and information about who will be present during a consultation may be particularly relevant to the patients' decision.

Patients seeing medical students in general practice settings 15 wanted to know the sex and number of students, although this information was rarely provided. Information about students' competence and experience and the likely nature of the consultation or examination were also felt necessary for truly informed consent.

\section{Conclusions}

Patients play an important part in medical education, but they want to be able to choose whether training doctors are involved in their care. There are certain items of information that patients want to know before deciding, and these are not always given. They want to know who will be present during their consultation, and this information might influence their decision as to whether to involve a training doctor. The gender of the training doctor is an important factor. There is a suggestion that male training doctors may be missing clinical experience in some clinics. Further research is indicated to investigate this, and to look at ways of improving the consenting process so that patients are more fully informed. Guidelines on how to obtain fully informed consent for involvement in medical training would be helpful. 
Statements on funding and competing interests

Funding The author received a research grant from the North West Society of Sexual Medicine and Family Planning. The research was, however, undertaken independently of this organisation.

Competing interests None identified.

Author's note

This article formed part of a dissertation for an MA in Clinical Education at Edge Hill College, University of Lancaster (author was awarded a distinction).

\section{Editor's note}

Two further articles by the same author to be published in the Journal in 2008 will explore the process of obtaining consent for patient involvement in doctor training, and look at what motivates patients to become involved.

References

1 Howe A, Anderson J. Involving patients in medical education. BMJ 2003; 327: 326-329.

2 Chipp E, Stoneley S, Cooper K. Clinical placements for medical students: factors affecting patients' involvement in medical education. Med Teach 2004; 26: 114-119.

3 O'Flynn N, Rymer J. Consent for teaching: the experience of women attending a gynaecology clinic. Med Educ 2003; 37: 1109-1114.

4 Ubel P, Silver-Isenstadt A. Are patients willing to participate in medical education? J Med Ethics 2000; 11: 230-235.

5 Santen SA, Hemphill RR, Prough EE, Perlowski AA. Do patients understand their physician's level of training? A survey of emergency department patients. Acad Med 2004; 79: 139-143.

6 Santen S, Hemphill R, Cindy S, Fletcher N. 'Sorry it's my first time!' Will patients consent to medical students learning procedures? Med Educ 2005; 39: 365-369.

7 Office for National Statistics. National Census, 2001. Neighbourhood statistics for Macclesfield (Local Authority). http://neighbourhood.statistics.gov.uk/dissemination/LeadKey Figures.do? $a=3 \& b=276900 \& c=$ Macclesfield $\& d=13 \& e=15$ $\& g=428795 \& \mathrm{i}=1001 \times 1003 \times 1004 \& \mathrm{~m}=0 \& \mathrm{enc}=1$ [Accessed 11 February 2007].

8 Rizk DE, El-Zubeir MA, Al-Dhaheri AM, Al-Mansouri FR, AlJenaibi HS. Determinants of women's choice of their obstetrician and gynecologist provider in the UAE. Acta Obstet Gynecol Scand 2005; 84: 48-53.

9 Zuckerman M, Navizedeh N, Feldman J, McCalla S, Minkoff H. Determinants of women's choice of obstetrician/gynecologist. $J$ Womens Health Gend Based Med 2002; 11: 175-180.

10 O'Flynn N, Rymer J. Women's attitudes to the sex of medical students in a gynaecology clinic: cross sectional survey. BMJ 2002; 325: 683-684.

11 Grant V. Patient involvement in clinical teaching. J Med Ethics 1994; 20: 244-250.

12 Seamark C, Blake S. Concerning women: questionnaire survey of consultations, embarrassment, and views on confidentiality in general practice among women in their teens, thirties and fifties. J Fam Plann Reprod Health Care 2005; 31: 31-33.

13 Quilliam S. Sexual health services. J Fam Plann Reprod Health Care 2004; 30: 265-266.

14 Hippisley-Cox J, Allen J, Pringle M, Ebdon D, McPhearson M, Churchill $\mathrm{D}$, et al. Association between teenage pregnancy rates and the age and sex of general practitioners: cross sectional survey in Trent 1994-7. BMJ 2000; 320: 842-845.

15 Benson J, Quince T, Hibble A, Fanshawe T, Emery J. Impact on patients of expanded, general practice based, student teaching: observational and qualitative study. BMJ 2005; 331: 89.

\section{Visit the Faculty Website at www.ffprhc.org.uk}

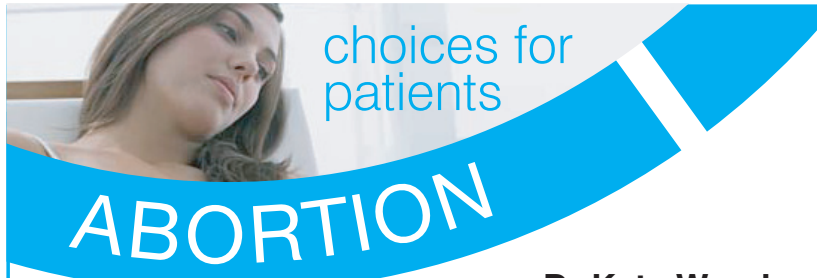

Dr Kate Worsley

Head of Medical Development - Marie Stopes International Many women who fall pregnant unexpectedly do not wish to continue with their pregnancy and it is important to provide them with choice, support and professional abortion services to help them get their lives back on track

Marie Stopes International now sees one third of all women seeking abortion in England and Wales. As experts in this field they have pioneered and modernised abortion provision making them first choice amongst healthcare professionals.

Medical abortion - currently one third of women between 4-9 weeks gestation having abortion, choose the abortion pill. At Marie Stopes centres this has been simplified to 2 visits over 2 days. Surgical abortion - women prefer a quick, convenient appointment and the majority are now choosing Marie Stopes one visit only appointments where the consultation and treatment are provided on the same day. A choice of anaesthesia including local, conscious sedation and general anaesthetic is also offered by the organisation.

A 24 hour appointment booking line and aftercare service on 08451203644 offers all the support and advice clients need.

Call for a Marie Stopes International GP Sexual Health Pack containing information on current abortion treatment choices and referral guidelines.

\section{4 www.mariestopes.org.uk}

working with you...
MARIE STOPES INTERNATIONAL

CONTRACEPTION • HEALTH SCREENING • STERILISATION • VASECTOMY • ABORTION

\section{NURSE ASSOCIATE MEMBERSHIP}

Associate Membership of the Faculty of Family Planning and Reproductive Health Care is open to all nurses with a special interest in contraception and reproductive health.

Article 3.9: Persons not medically qualified but who have made an important contribution to and are working in the sphere of the Faculty and medical practitioners who are permanently retired from clinical practice, due to age or ill health, may on application to the Council be accepted for Associate Membership.

The annual subscription from January 2008 onwards costs $£ 47$ and entitles Associate Members to copies of the Journal of Family Planning and Reproductive Health Care (plus free access to the online journal, managed by Ingenta) and access to the members' enquiry service.

The Associate Membership application form is available for downloading on the Faculty website at www.ffprhc.org.uk. 